\title{
Are synthetic pheromone captures predictive of parasitoid densities as a kairomonal attracted tool?
}

\begin{abstract}
Abundance of White Peach scale (WPS), Pseudaulacaspis pentagona (Targioni-Tozzetti) and San José scale (SJS), Diaspidiotus perniciosus (Comstock) (Hemiptera: Diaspididae) adult males and their attracted parasitoids were monitored using pheromone and sticky tape traps in an orchard of Budapest, Hungary, during 2010. In this study, we tried answer on the question raised whether synthetic commercial pheromones of WSP or SJS could work as a kairomonal stimulant and positively attract higher numbers of the specialized parasitoids. Although pheromone traps attracted a wide range of parasitoid species, most of them were accidentally. However, the parasitoid Thomsonisca amathus (Walker) (Hymenoptera: Encyrtidae) and the parasitoid Encarsia perniciosi (Tower) (Hymenoptera: Aphelinidae) significantly respond to the sex pheromones of WPS and SJS, respectively, suggesting that they may play an important role in host location.
\end{abstract}

Riassunto - Le catture di un feromone sintetico possono fornire indicazioni sulla densità di un parassitoide agendo come uno strumento attrattivo kairomonale?

La densità di maschi adulti di Pseudaulacaspis pentagona (WPS) (Targioni-Tozzetti) e di Diaspidiotus perniciosus (SIS) (Comstock) (Hemiptera: Diaspididae) e dei loro parassitoidi è stata monitorata nel corso del 2010, utilizzando feromoni e trappole collanti in un frutteto di Budapest (Ungheria). Scopom del lavoro è stato quello di rispondere alla questione se il feromone sintetico dei due Diaspini agisca come kairomone, attraendo un elevato numero di parassitoidi specializzati. Sebbene si verifichi ciò, la maggior parte dei parassitoidi viene catturata occasionalmente. Tuttavia, l'Imenottero Encirtide Thomsonisca amathus (Walker) e l'Afelinide Encarsia perniciosi (Tower), rispondono in modo significativo al feromone sessuale, rispettivamente, di WPS e di SIS; ciò suggerisce che il feromone può svolgere un ruolo importante nell'individuazione dell'ospite.

Key words: Thomsonisca amathus, Encarsia perniciosi, Pseudaulacaspis pentagona, Diaspidiotus perniciosus, Europe. 


\section{INTRODUCTION}

The white peach scale (WPS), Pseudaulacaspis pentagona (Targioni-Tozzetti, 1880) (Hemiptera: Diaspididae) is one of the most important pest of ornamentals and fruit trees (about 380 host plant records) all over the world (Ben-Dov et al., 2010; Kosztarab and Kozár, 1988; Kozár, 2009; Saber et al., 2010). The other important armored scale insect is the San José scale (SJS), Diaspidiotus perniciosus (Comstock, 1881) (Hemiptera: Diaspididae) which attacks at least 34 families of hosts (over 700 species) and it has become a cosmopolitan pest in deciduous fruit and nut orchards (Ben-Dov et al., 2010; Konstantinova et al., 1982).

Pheromones are one of the major components of ecologically based insect pest management (Kozár, 1997; Howse et al., 1998). Effectively, the use of pheromones for monitoring, mass trapping, mating disruption, or lure-and-kill has been investigated or developed during recent decades (Smetnik, 1991; Kozár, 2009). Parasitoids often use chemical stimuli, called infochemicals (Mendel et al., 2004; Franco et al., 2008) when they are searching for their hosts, and these infochemicals can be associated to their host, such in the case with the host sex pheromone (reviewed in Godfray, 1994). Parasitoids can orientate towards these cues over a moderate distance that they associate in some way with the host.

Although pheromones are generally viewed as environmentally sound, some practical problems regarding their safety could arise from their kairomonal activity. This is of importance, as catching large numbers could affect negatively the densities of these beneficial insects, and potentially result in increases in pest populations. However, this aspect has not been studied in detail to date in scale insects. Matuhira and Kouzaki (2001) reported that Thomsonisca typica Mercet, 1920 was the only parasitoid attracted by the synthetic sex pheromone of $P$. pentagona in Japan. They found that a half of attracted female wasps had well developed ovaries, suggesting that they use the sex pheromone as a kairomone in order to find a host scale. On the other hand, when sex pheromones are used as a pest management strategy, the potential negative effects on the populations of natural enemies must take into consideration. As an alternative, using of pheromone lure alone in the infested trees, as an attractive kairomonal tool, could help to increase the efficiency of parasitoids in biocontrol rather than to reduce their populations. The attractively of parasitoids T. amathus was observed in the pheromone traps of WPS during 2009 (Kozár, personal observations).

The objective of this study was to evaluate the effectiveness of commercial pheromones of WSP and SJS for catching parasitoids as kairomonal stimulants.

\section{MATERIALS AND METHODS}

The effect of baited traps with synthetic pheromone dispensers of $P$. pentagona (WSP) and D. perniciosus (SJS) as well as the non baited sticky traps on the numbers of captured males and parasitoids was studied in Budapest (Hungary) during 2010. The trees (Prunus sp., Malus pumila Mill., Syringa vulgaris L.) in surrounding area were 


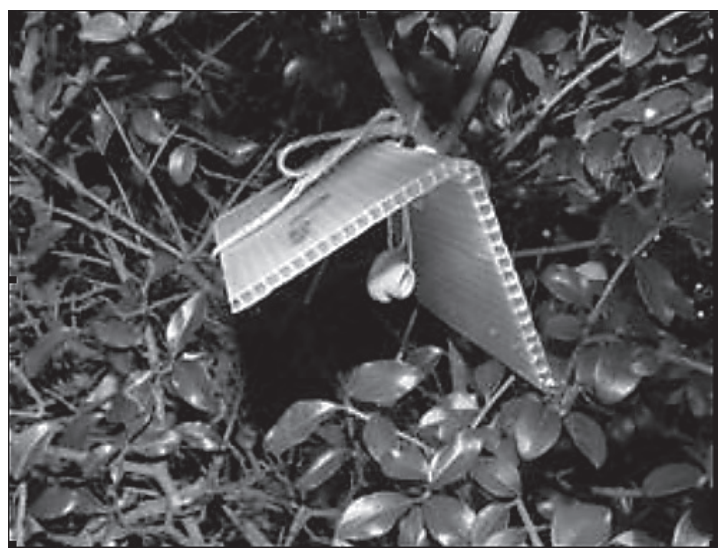

Fig. 1 - Hungarian tent trap with the pheromone dispenser (Photo Dr. I. Tóbiás).

infested with both scales. The traps were of the Hungarian tent trap design $(10 \times 10$ $\mathrm{cm}$, plastic square with plastic glue). Commercial pheromone dispensers of WSP and SJS were obtained from Biochemtech (Biochemtech Ltd. Kishinev, Moldavia) pheromone dispensers, with Soveurode (Witasek Pflanzenschutz GmbH, Austria) glue. The compound of the sex pheromone of WPS is (Z)-3,9-dimethy-6-isopropeny13,9-decadien-1-yl propanoate (WPS-1) (Heath et al., 1980). The compounds of SJS pheromone are: (Z)-3,7-dimethy1-2,7-octadien-1-y1 propanoate (SJS-I; ca. 48\%) and 7-methyl-3-methylene-7-octen-1-y1 propanoate (SJS-II; ca. 47\%) (Gieselmann et al., 1979). The dispensers of both pheromones were left in the field for c. 4-8 weeks and then replaced according to Rice et al., (1982). The pheromone dispenser was suspended c. 3-4 cm below the trap (Figure 1). The sticky tape trap squares were replaced every time the traps were inspected and the number of scale insect males and their attracted parasitoids were counted in the laboratory using stereo binocular microscope (Figure 2).
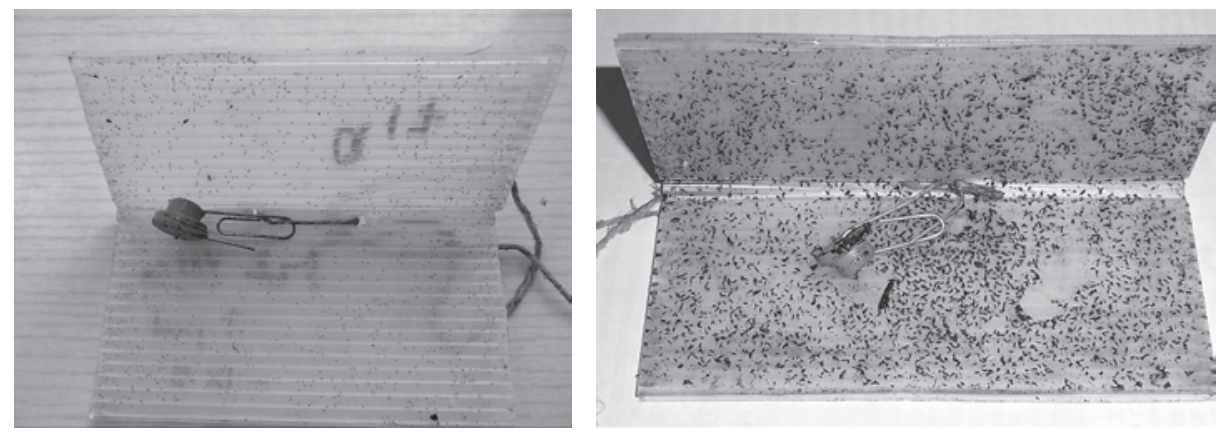

Fig. 2 - The males of P. pentagona (left) and the parasitoids (right) captured on the internal white plastic surfaces of the pheromone trap. 
For each host, three pheromone traps (treatment) and three sticky traps (control) were monitored for each data as recommended by Rice et al. (1982). Traps were placed in the orchards on 1 June till 13 November 2010. The pheromone and sticky traps were located at minimum five trees from an orchard border and at a height of about $2 \mathrm{~m}$ from the ground (Rice et al., 1982).

For each diaspidid host, the mean WSP and SJS males and their associated parasitoids captured in the three pheromone traps and the three associated sticky tape traps within each date of 2010 contributed for the regression analyses. Regression analyses were performed by using SPSS to determine the relationship between the WSP males and the parasitoid Thomsonisca amathus (Walker, 1838) as well as between SJS males and the parasitoid Encarsia perniciosi (Tower, 1832) captured in the pheromone traps during 2010. Data were analyzed by using One way ANOVA followed by post hoc StudentNewmann- Keul's multiple-range tests $(\alpha=0.05)$ (CoStat, 2004). The WPS and SJS pheromones have relative volatiles, therefore to test the pheromone response of WPS and SJS males and the kairomonal response of T. amathus wasps for both pheromones, the data were analyzed using independent sample $t$ test. Data were $\ln (\mathrm{x}+1)$ transformed prior to analysis to normalize the residuals. Bars in the graphs were followed with mean numbers of catches prior to transformation.

\section{RESULTS}

A wide and low range of WSP and SJS male densities were recorded in pheromone traps in the orchard monitored during the different periods of study. The highest number of WPS and SJS male catches was recorded during July. The $t$ test revealed that there were significant differences in male catches of each diaspidid host between pheromone and sticky traps during different swarming periods. The statistical analysis showed that there were significant differences between parasitoid species captured in pheromone traps within each period of swarming, but not in sticky traps (Figures 3,4). In addition, there was a significant difference between the mean numbers of WPS and SJS male catches by pheromone traps during the period of study $(t=4.01 P<0.0001)$ (Figure 5).

A wide range of specialized aphelinid parasitoid species was recorded in the traps baited with WPS or SJS pheromones. The endoparasitoid, Encarsia berlesei (Howard, 1906) and ectoparasitoid Aphytis proclia (Walker, 1839) in WPS traps; and the endoparasitoid E. perniciosi and A. proclia in SJS traps were recorded in few numbers in both pheromone and sticky traps. On the other hand, the encyrtid endoparasitoid $T$. amathus was recorded in high numbers in sex pheromone traps of WPS, while the encyrtid endoparasitoid Coccophagous sp. was recorded in very few samples in traps of both host.

In the WPS and SJS pheromone traps, the parasitoids T. amathus and E.perniciosi were captured in significantly higher numbers than other species, respectively (Figure 3 ). There were significant differences in the number of T. amathus captures between pheromone and sticky traps of WPS $(F=189.44, d f=3,11, P<0.001)$ (Figure 4). In WPS pheromone traps, there were significant differences between parasitoid species captures 


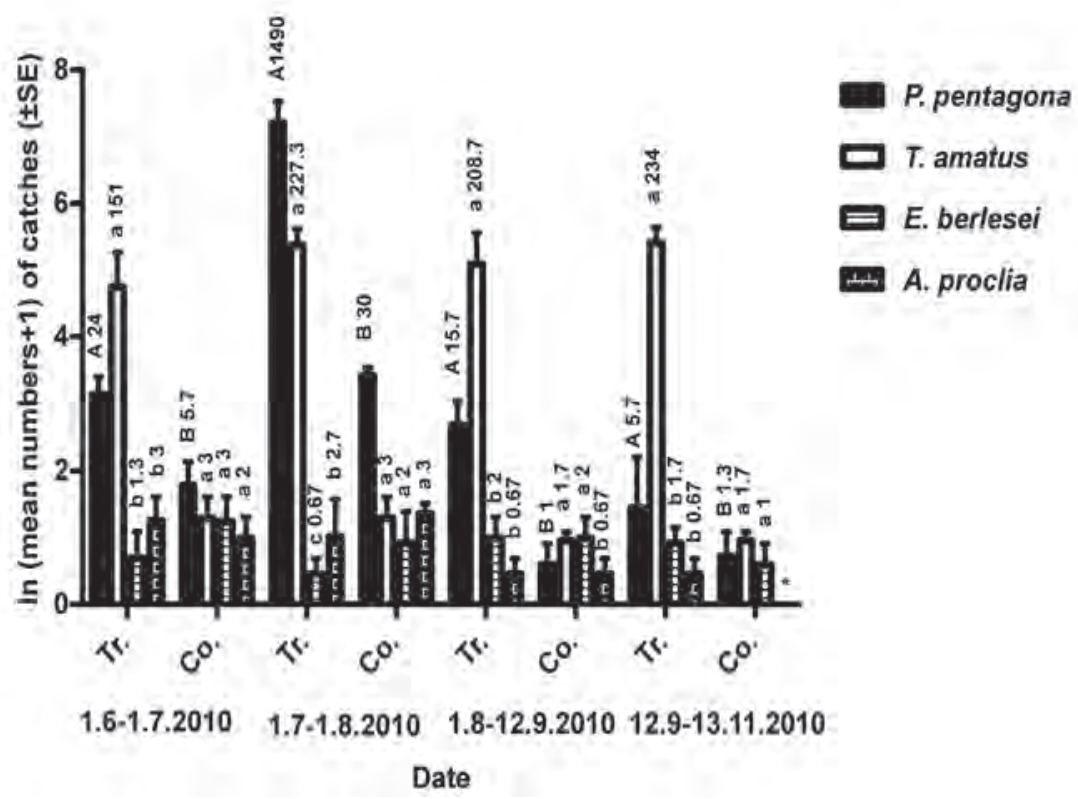

Fig. 3 - $\ln$ (mean numbers +1$)$ of $P$. pentagona males and parasitoids captured in pheromone (treatment) and sticky (control) traps during the different swarming dates in 2010. Bars followed with the different small (between parasitoid species within each treatment or control) and capital (between treatment and control for each host species) letters (letters followed with mean numbers prior to transformation) within each date are significantly different at $\alpha=0.05$. *Data equal to 0 and not statistically enough for comparison.

within each period of study, and the same significant differences were also performed in SJS pheromone traps (Figures 3,4). The mean numbers of T. amathus wasps significantly differed between WPS and SJS pheromone traps $(t=13.19, d f=1,11, P<0.001$; Figure 5 ), while there were no significant differentiation between sticky traps and SJS trap. This information shows that catches of T. amathus by SJS traps was accidentally.

There were no significant relationships between WPS males and T. amatus wasps $(n=12, r=0.20, P>0.05)$ as well as between SJS males and E. perniciosi wasps $(n=12$, $r=0.42 ; P>0.05)$ during the period of study.

\section{DISCUSSION AND CONCLUSIONS}

The parasitoids $T$. amathus and E. perniciosi significantly respond to the sex pheromones of WPS and SJS compared with other species, suggesting that they may play a role in host location (Tashiro et al., 1979). This kairomonal activity is previously demonstrated in insect parasitoids in Japan, where the parasitoid T. amathus responded 


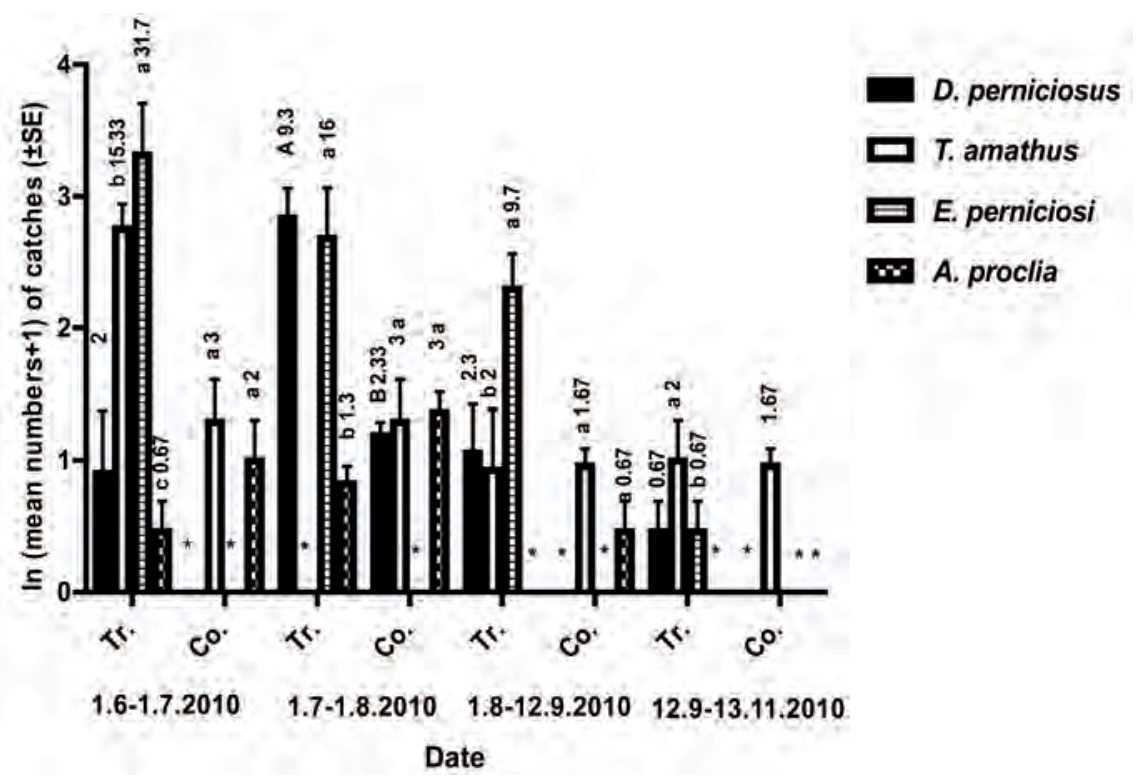

Fig. 4 - ln (numbers+1) of D. perniciosus males and their collected parasitoids captured in pheromone (treatment) and sticky (control) traps during the periods of activity in 2010. Bars followed with the different small (between parasitoid species within each treatment) and capital (between treatment and control for each host species) letters within each date are significantly differed at $\alpha=0.05$. $*$ Data equal to 0 and not statistically enough for comparison.

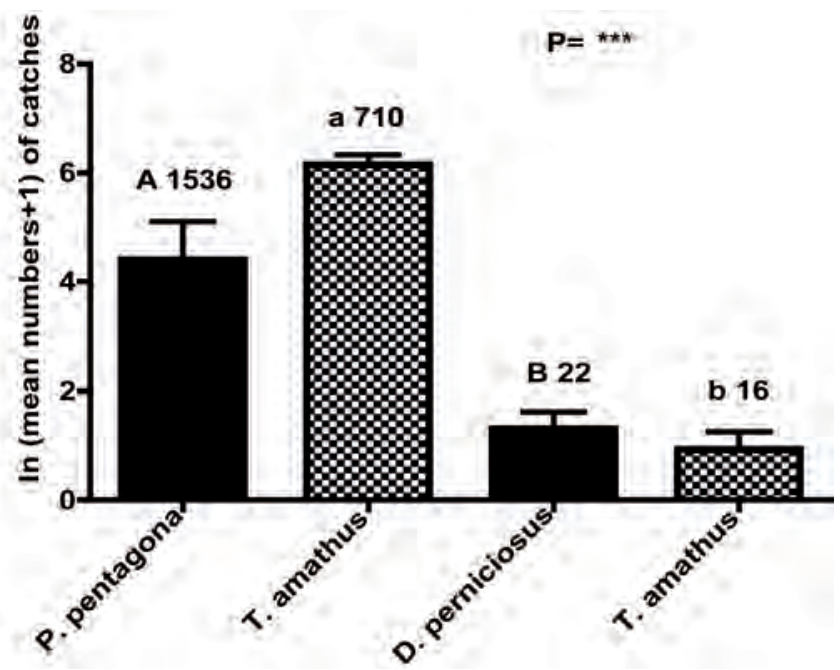

Fig. 5 - $\ln ($ mean numbers +1$)( \pm \mathrm{SE})$ of $T$. amathus wasps captured in pheromone traps of $P$. pentagona and $D$. perniciosus during 2010 . Bars followed with the different small (+ total catches) or capital letters (+ total catches in 2010) are significantly differed at $\alpha=0.05$. 
to the WPS pheromone (Matuhira et al.,2001). T. amathus is a common parasitoid of the diaspidid species, Chionaspis salicis (Linnaeus, 1758), C. lepineyi Balachowsky 1928, and P.pentagona in central Europe (Erdös, 1957; Kosztarab and Kozár, 1988; Zahradnik, 1972; Trjapitzin, 1978; Subba Rao, 1979). In this study, WPS pheromone seems to be a kairomone for T. amathus. This was because higher numbers of T. amathus wasps were attracted to WPS pheromone than SJS pheromone, since that there were significant differences between pheromone and sticky trap captures, while these differences were absent in case of SJS. Furthermore, the highest number of T. amathus wasps was recorded during July in WPS and SJS pheromone traps; however, there was high variation in its population in the pheromone traps of both hosts (Figures 3,4). Therefore, it seems to be accidentally crossed to SJS pheromone traps during its swarming towards WPS pheromone. The WSP pheromone may be having a kairomonal function for attracting high numbers of T. amathus, and thus the effects of both functions may be may be antagonistic or synergistic.

In conclusion, our study provides insights on the kairomonal responses of parasitoids to synthetic sex pheromones. The synthetic WPS pheromone had a higher kairomonal effect on T. amathus; however, SJS pheromone had the same effect on E. perniciosi, suggesting that they may play a role in host location. Our results are the first to capture T. amathus using the synthetic pheromone of SJS, however this was thought accidentally.

\section{ACKNOWLEDGEMENTS}

The authors are grateful to the Hungarian Scholarship Broad (HSB) for financial support of this work by a post-doc partnership grant for M. H. Bayoumy at the Hungarian Academy of Sciences, Plant Protection Institute, Zoology Department, Budapest. We also thank the OTKA for financial support of the project no. 75889. Thanks to Zsuzsanna Konczné Benedicty (Hungarian Academy of Sciences, Plant Protection Institute, Zoology Department, Budapest) for help in counting males and Kinga Fetykó (Hungarian Academy of Sciences, Plant Protection Institute, Zoology Department, Budapest) for trapping works.

Thanks also to George Japoshvili (Entomology and Biocontrol Center, Ilia State University, Georgia), Lászió Zoltán (Department of Taxonomy and Ecology, Babes, Bolyai University, Romania), and I. Tóbias (Hungarian Academy of Sciences, Plant Protection Institute, Zoology Department, Budapest) for identifying the encyrtid parasitoid, Thomsonisca amathus.

\section{REFERENCES}

Ben-Dov, Y., Miller, D. R., Gibson G.A.P., 2010 - ScaleNet, a database of scale insects of the world: http://www.Sel.Barc.Usda.Gov.ScalenetScalenet.

CoStat Software 2004 - Microcomputer program analysis, version 6.3. CoHort Software, Berkely, CA, USA. 
ERDös, J. 1957 - Miscellanea chalcidologica hungarica. Annales Historico-Naturales Musei Nationalis Hungarici (Series Nova) 8: 368

Franco J.C., Silva E.B., Cortegano E., Campos L., Branco M., Zada A., Mendel Z., 2008 - Kairomonal response of the parasitoid Anagyrus spec. nov. near pseudococci to the sex pheromone of the vine mealybug. - Entomologia Experimentalis et Applicata 126: 122-130.

Gieselmann M.J., Rice R.E., Jones R.A., Roelofs W.L., 1979 - Sex pheromone of the San Jose scale. - Journal of Chemical Ecology 5: 891-900.

GODFRAY H.C.J., 1994 - Parasitoids: behavioral and evolutionary ecology. Princeton University Press, Princeton, New Jersey.

Heath R.R., Doolittle R.E., Sonnet P.E., Tumlinson J.H., 1980 - Sex pheromone of the white peach scale: Highly stereoselective synthesis of the stereoisomers of pentagonal propionate. - Journal of Organic Chemistry 45: 2910-2912.

Howse P., Stevens I., Jones O., 1998 - Insect Pheromones and Their Use in Pest Management. Chapman \& Hall, London.

Konstantinova G.M., Maximova V.H., KozÁR F., 1982 - Integrated protection of groves and orchards from the San Jose scale Aspidiotus perniciosus, fruit pest, USSR. (In Russian). Zashchita rastenii. Moscow 3: 24-25.

Kosztarab M., KozÁr F., 1988 - Scale Insects of Central Europe. Akadémiai Kiadó, Budapest, $456 \mathrm{pp}$.

KozÁR F., 1997 - Insects in a changing World. - Acta Phytopathologica et Entomologica Hungarica 32: 129-139.

KozÁr F., 2009 - Scale species (Hemiptera, Coccoidea) and climate change studies on Hungarian highways. - Növényvédelem 45: 577-588.

KozÁr F., Mani F., Hippe C., 2009 - Daily rhythm of emergence and flight of males of Pseudaulacaspis pentagona (Hemiptera: Coccoidea). - Acta Phytopathologica et Entomologica Hungarica 44: 185-191.

LEWIS W. J., MARTIN J., 1990 - Semiochemicals for use with parasitoids: status and future. - Journal of Chemical Ecology 16: 3067-3089.

MATUHIRA K., KouZAKI Y., 2001 - Biological control of the mulberry scale, Pseudaulacaspis pentagona (Targion), using synthetic sex pheromone and insecticide sensitivity of its natural enemy parasitoid wasp. - Bulletin of the Kagoshima Tea Experiment Station 15: 13-21.

Mendel Z., Assael F., Dunkelblum E., 2004 - Kairomonal attraction of predatory bugs (Heteroptera: Anthocoridae) and brown lacewings (Neuroptera: Hemerobiidae) to sex pheromones of Matsucoccus species (Hemiptera: Matsucoccidae). - Biological Control 30: $134-140$.

Rice R.E., FlaheRTy D.L., Jones R.A., 1982 - Monitoring and modeling San Jose scale. California Agriculture, Jan.-Feb.: 13-14.

SABER F.M.M., RAWHEIA H.R., SAHAR A.A., 2010 - Seasonal fluctuation of the white peach scale insect, Pseudulacaspis pentagona (Targioni) and its associated parasitoid, Aphytis sp. At Mett-Ghamer, Dakahlyia Governorate, Egypt. Egyptian Academy. - Journal of biological Sciences 3: 1-9.

SMETNIK A.I., 1991 - [Pheromones of scales.] (In Russian). - Quarantine Pests, Diseases and Weeds I: 92-129.

SubBa Rao B.R., 1979 - Taxonomic studies on some encyrtid genera (Hymenoptera: Chalcidoidea: Encyrtidae).- Oriental Insects 13: 139-148

Tashiro H., Gieselmann M.J., Roelos W.L., 1979 - Residual activity of a California red scale pheromone component. - Environmental Entomology 8: 931-934. 
TRJAPITZIN V. A., 1978 - Superfamily Chalcidoidea. In Insect determination manual for the European part of USSR, by Medvedeva, G.S. Publ. Nauka, Leningrad. Hymenoptera, vol 3, $2^{\text {nd }}$ part. (In Russian). P. 28-538.

Vinson S.B., 1991 - Chemical signal used by parasitoids. 4th European Workshop-Perugia 3-5 April, REDIA, 74 (3) "Appendice".

ZAHRADNIK J., 1972 - Überfamilic Archaeococciodea, Neococcoidea, Pseudococcidea, Eriococcidae, Diaspididae. In Die Forstschädling Europas by Schwenke, W. Paul Parey Publ. HamburgBerlin 1: 391-405, 422-446.

Mohamed Hassan Bayoumy, Entomology Department, Faculty of Agriculture, Mansoura University, Mansoura 35516, Egypt \& Plant Protection Institute of Hungarian Academy of Sciences, Budapest H-1525, P.O. Box: 102. E-mail: marsamarium@yahoo.com

Mehmet BoRa KYdAn, Yüzüncü Yıl Üniversity, Agriculture Faculty, Plant Protection Department, 65080 Kampus - Van, Turkey. E-mail: bkaydan@hotmail.com

FERENC KoZÁR, Plant Protection Institute of Hungarian Academy of Sciences, Budapest H-1525, P.O. Box: 102.E-mail:h2405koz@ella.hu 